(อ) OPEN ACCESS

\title{
Optimal management of acute coronary syndromes in the era of COVID-19
}

\author{
Sukhjinder Singh Nijjer (1) ${ }^{1,2}$ Ricardo Petraco, ${ }^{2}$ Sayan Sen $^{2}$
}

${ }^{1}$ Cardiology, Chelsea \& Westminster NHS Foundation Trust, London, UK ${ }^{2}$ Cardiology, Hammersmith Hospital, Imperial College Healthcare NHS Trust, London, UK

\section{Correspondence to} Dr Sukhjinder Singh Nijjer, International Centre of Circulatory Health, Imperial College London, Hammersmith Hospital, London W12 OHS, United Kingdom; s.nijjer@imperial.ac.uk

Published Online First 2 September 2020

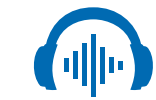

Listen to Podcast heart.bmj.com
Check for updates

(C) Author(s) (or their employer(s)) 2020. Re-use permitted under CC BY-NC. No commercial re-use. See rights and permissions. Published by BMJ.

To cite: Nijjer SS, Petraco R, Sen S. Heart 2020;106:1609-1616.

\section{INTRODUCTION}

The coronavirus pandemic (COVID-19) has had unprecedented impact on healthcare systems, including acute cardiology services. ${ }^{12}$ COVID-19 directly leads to cardiac complications in those patients with underlying heart disease or cardiac risk factors. COVID-19 indirectly impacts patients through the required change in healthcare resource allocation and the need for social distancing. A reduction in health-seeking behaviour ${ }^{34}$ reduced attendances for cardiac emergencies, ${ }^{56}$ and reduction in traditional chronic care will have implications that extend beyond the infective reach of the virus. Therefore, cardiovascular care during the pandemic should remain a priority to mitigate the significant morbidity and mortality from both the direct and indirect effects of COVID19. ${ }^{7}$ As future coronavirus waves are anticipated, it is prescient to review its impact on the delivery of cardiovascular care, in particular the management of acute coronary syndromes (ACS).

\section{CARDIOVASCULAR CONCERNS IN COVID-19}

Early reports suggested a strong relationship between traditional cardiovascular risk factors and poor outcomes from COVID-19. ${ }^{89}$ COVID-19 related myocardial injury is evident in postmortems. ${ }^{10}$ Those with critical illness demonstrate elevation of troponin and B-type natriuretic peptide (BNP) levels and rising levels correlate to poorer clinical outcomes. ${ }^{11} 12$

The mechanisms of myocardial injury remain poorly understood but candidates may involve ACE2 expression within the myocardium and coronary vessels triggering local inflammation, hypercoagulopathy and thrombosis. Coronary thrombosis will cause ACS and localised ischaemia in the form a type I myocardial infarction (MI). ${ }^{11}$ Ischaemia may also result from respiratory failure and hypoxia; in the context of underlying coronary disease, troponin rise may reflect a type II MI due to supply/demand mismatch. ${ }^{13}$ Pulmonary emboli may also occur, driving elevated pulmonary pressures with right ventricular strain. ${ }^{14}$ An immunemediated inflammatory response appears to drive a secondary myocarditis and contributes to acute heart failure and multiorgan failure. ${ }^{15}$ The COVID-19 myocarditis generates striking ECG changes with marked and even regional ST elevation ('STEMI-mimic'). Also, sympathetic drive may drive a Takutsubo-style cardiomyopathy or drive cardiac arrhythmia.
Learning objectives

- Identify the cardiovascular complications of COVID-19.

- Identify the current management of acute coronary syndromes (ACS).

- Identify the challenges in delivering treatment of ACS in the context of COVID-19.

- Describe the best practice for primary angioplasty for ST-elevation myocardial infarction in the COVID-19 era.

- Describe scenarios where thrombolysis should be considered.

\section{ACUTE CORONARY SYNDROMES}

In the pre-COVID-19 era, diagnosis of ACS relied on classical symptoms of chest discomfort (often associated autonomic features), characteristic electrocardiographic features and the rise in cardiac biomarkers (typically troponin). Management requires antiplatelets (aspirin with a potent $\mathrm{P} 2 \mathrm{Y}_{12}$ antagonist such as clopidogrel, prasugrel or ticagrelor), injectable anticoagulants (such as fondaparinux) and modification of cardiac demand (with beta-blockers). ${ }^{12}{ }^{13}$ Statins are given early as they may promote plaque stabilisation. While initial reports raised concerns about the use of ACE inhibitor and angiotensin receptor in patients with COVID-19, ${ }^{16}$ age-corrected models have not supported this, and ARBs may even have a protective role. ${ }^{17}$

Those with higher risk features such as significant troponin markers, ongoing ECG changes or high GRACE scores are offered invasive angiography as revascularisation reduces poor outcomes including reinfarction. ${ }^{18}{ }^{19}$ In ST-elevation myocardial infarction (STEMI), immediate revascularisation with primary percutaneous coronary intervention (PCI) is essential. Untreated, STEMI has high mortality and risks mechanical complications such as mitral regurgitation or ventricular septal defects. ${ }^{18}$ Doorto-balloon time should be less than 60 min where feasible. Non-ST elevation myocardial infarction (NSTEMI) should have angiography within 72 hours, ideally sooner.

All these factors remain true in the COVID-19 era with the additional assessment of infective status and appropriate protection of staff. COVID-19 treatment algorithms have incorporated the use of anticoagulants given the thrombotic risk. ${ }^{20}$ Ischaemic events may be reducedby the addition of rivaroxaban $2.5 \mathrm{mg}{ }^{21}$ twice daily and ongoing studies are assessing this in the COVID-19 era. 
While chest pain is common in COVID-19, symptoms of true MI remain distinct and detectable on assessment of history. The principle issue is distinguishing such type I MI events from troponin elevation due to arrhythmia, heart failure, myocarditis, pericarditis or systemic illness (type II MI). ${ }^{13}$ Clinical assessment, serial ECG and troponin measurement are key to diagnosis. In the context of COVID-19, conservative management may be appropriate for non-true ACS.

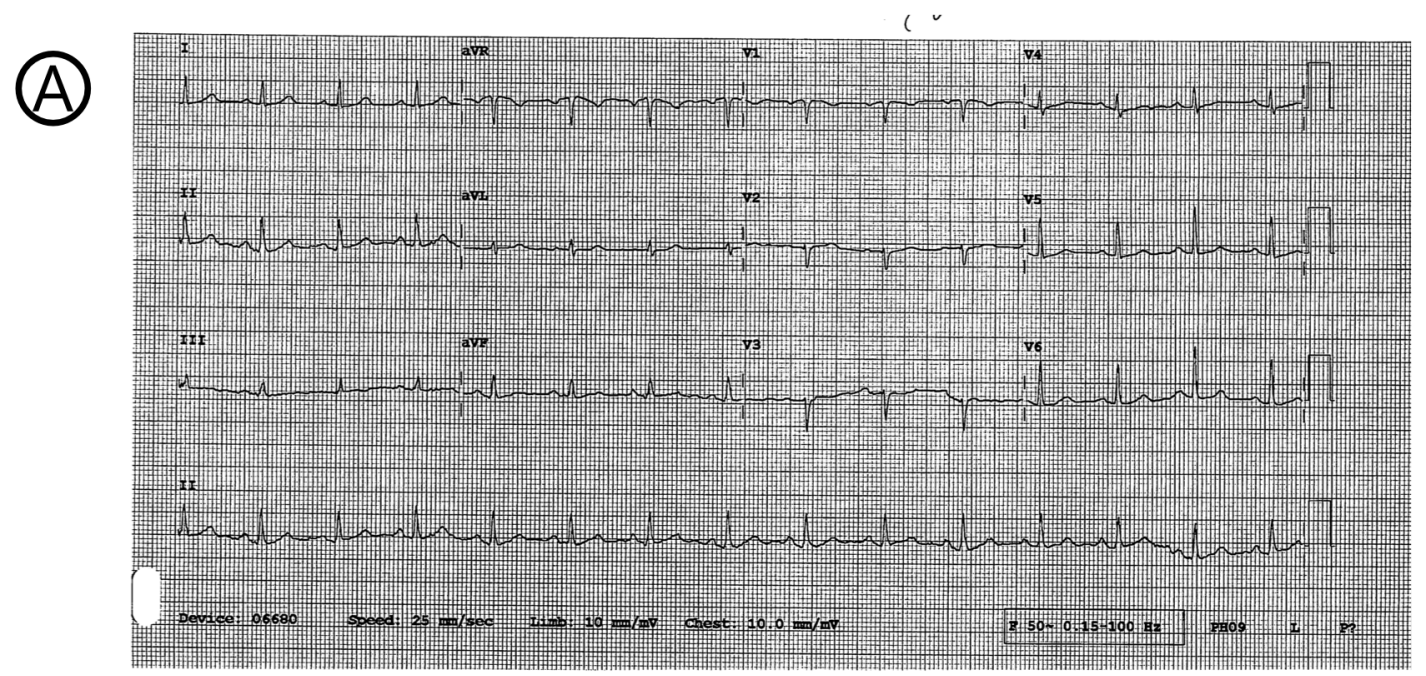

(B)

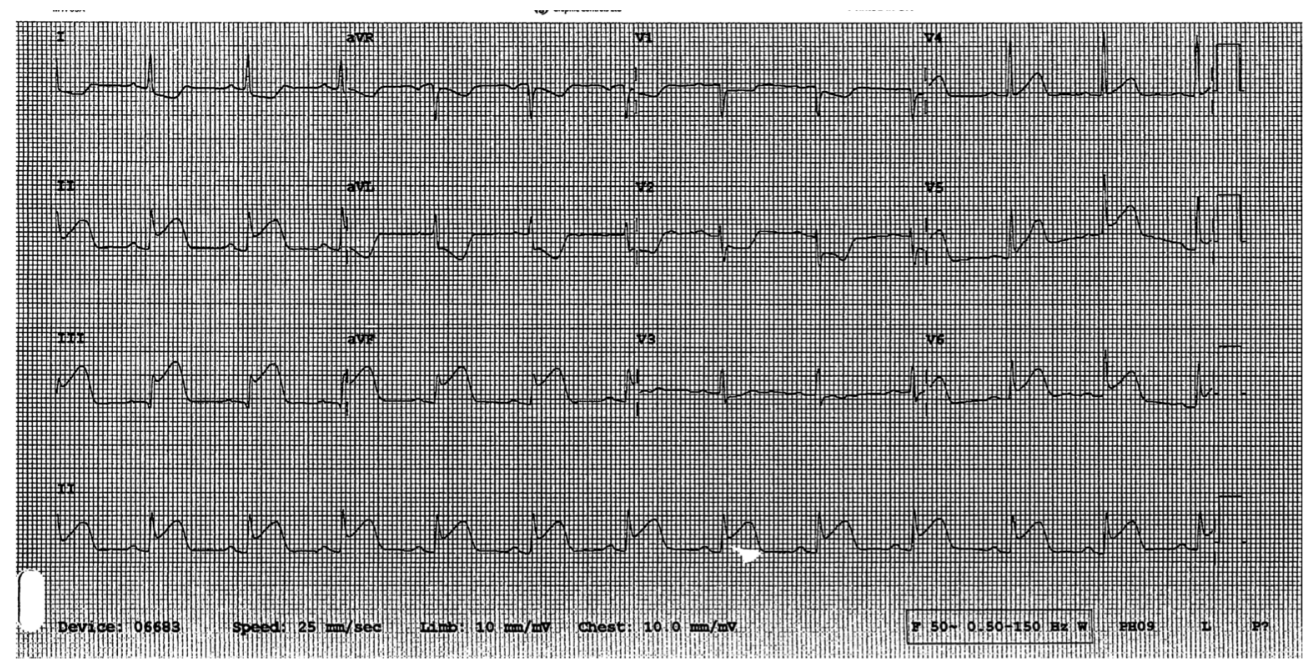

(C)

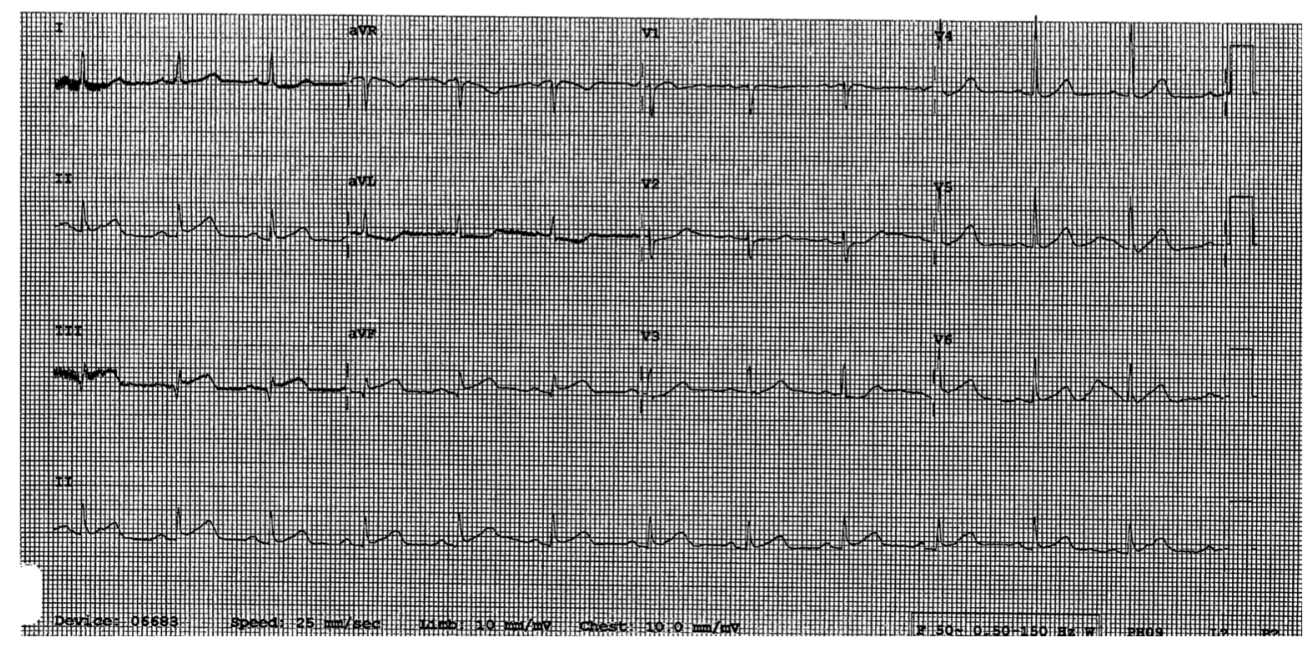

Figure 1 Electrocardiographs of patient with COVID-19 developing ST elevation myocardial infarction. (A) Baseline electrocardiograph on admission. (B) The patient developed severe central crushing chest pain while on continuous positive airways pressure. ST elevation is evident in the inferior leads with reciprocal ST depression anteriorly. (C) Following alteplase and heparin, there is evidence of reperfusion with over $50 \%$ reduction in ST elevation in the inferior leads. 
Point of care echocardiography can support decision making: the presence of regional wall motion changes would suggest typical ACS. Since echocardiography is an intimate examination with a sustained period of contact between patient and healthcare worker, there is increased risk of viral transmission, and full personal protective equipment (PPE) is advocated. Focused scans with limited views to answer the question are appropriate. Patients should wear masks during scanning and during their assessment and treatment.

\section{REPERFUSION FOR STEMI}

In STEMI, rapid mechanical reperfusion through primary percutaneous coronary intervention (PPCI) is the preferred treatment option. ${ }^{22}$ The National Health Service and the British Cardiovascular Intervention Society have reiterated that PPCI remains the treatment of choice for STEMI in the COVID-19 era. ${ }^{23}$ In the UK, most cardiac networks have STEMI diagnosed by ambulance services, and patients are taken directly to designated cardiac catheter laboratories. Occasionally,
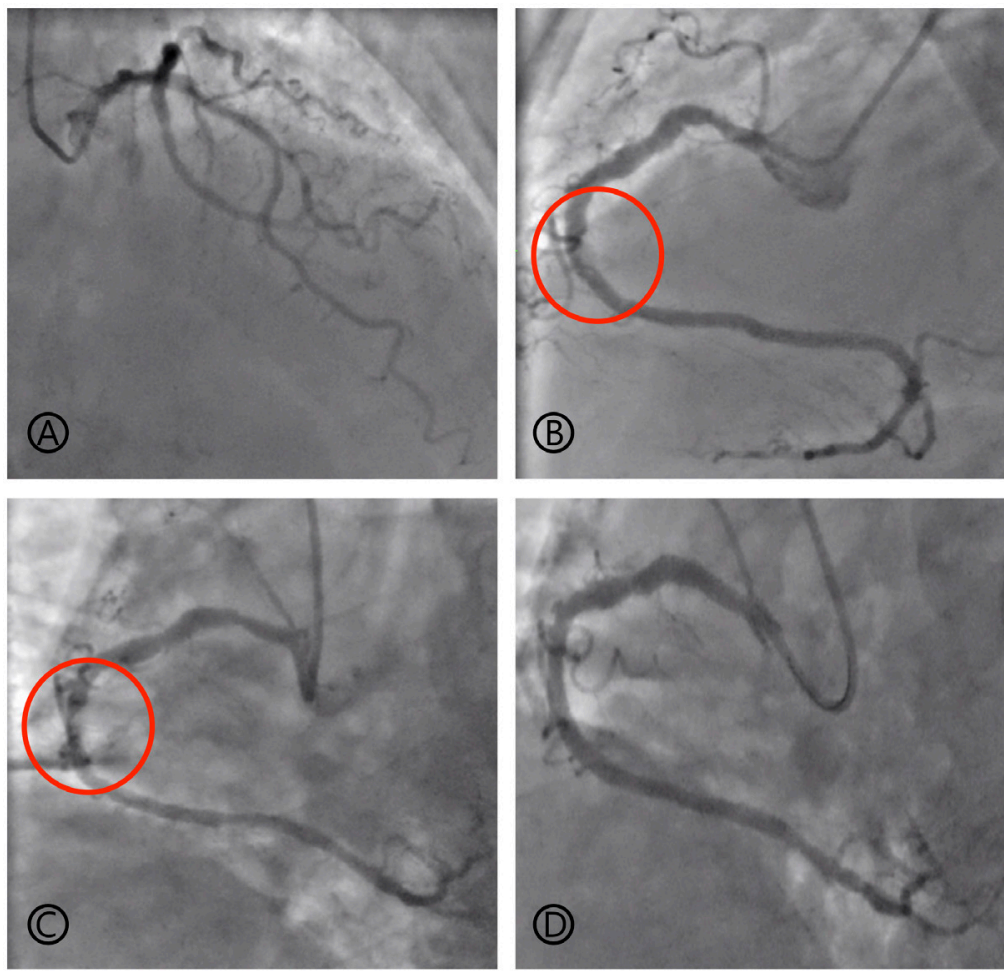

Figure 2 Stills from invasive coronary angiography in stabilised patient with COVID-19 after thrombolysis for STEMI. Coronary angiography was performed via the right radial artery. $(A)$ the left coronary tree had diffuse disease with moderate to severe disease in a second diagonal artery. $A$ prior stent in the LAD was patent. ( $B$ and C) A dominant right coronary artery had a moderate to severe proximal stenosis with a recanalised thrombotic lesion in the midvessel. (D) The proximal and midvessel lesions are stented with $3.5 \mathrm{~mm}$ diameter drug-eluting stents that are optimised with $4.0 \mathrm{~mm}$ non-compliant balloons. STEMI, ST-elevation myocardial infarction. patients may require acute transfer from district general hospitals into hub hospitals if the first hospital cannot offer revascularisation within a timely fashion. Typically, critical care ambulances are required for this.

As there is an asymptomatic period in which infected patients are shedding the virus, those presenting as emergency STEMI could drive viral transmission to first responders and those performing PPCI. COVID-19 diagnostic tools are not sufficiently rapid yet to permit screening prior to emergency PPCI for STEMI, and while screening with CT-thorax is useful in more elective settings, it is unfeasible in a STEMI setting. As PPCI can involve cardiac arrest, a recognised 'aerosol generating procedure', it is agreed that full PPE is recommended for all those performing PPCI. ${ }^{23} 24$ Services should consider shielding members of staff at highest risk from COVID-19: those with lung conditions or those over the age of 65 years have been redeployed to non-patient-facing activities appropriately.

PPCI should be performed with reperfusion within $120 \mathrm{~min}$ of symptom onset and within $60 \mathrm{~min}$ of arrival at a PPCI capable centre. ${ }^{2021}$ Radial access is preferred to facilitate early patient ambulation. Observational data suggest those with COVID-19 have a greater burden of thrombus: multivessel thrombosis and stent thrombosis rates are higher. ${ }^{25}$ Higher rates of aspiration thrombectomy and greater need for GPIIb/IIIa and higher doses of intraprocedural heparin are all reported. ${ }^{25}$ Prolonged hospitalisation and greater mortality is seen in those with COVID-19 and STEMI. ${ }^{25} 26$

A dedicated catheter laboratory is recommended, and all possible equipment should be available within this to limit staff having to fetch equipment and potentially spread the virus. A designated area for donning and doffing PPE is essential; staff should observe each other to provide support in this process. All team members should have sufficient PPE with FF2 or FFP3 mask, gown, goggles and/or visor. As PPE remains scarce, some may choose to limit PPE usage to operators only. However, in the event of a cardiac arrest, team members will need to leave the cardiac catheter lab to don PPE before exposure to Cardiopulmonary resuscitation (CPR) manoeuvres.

Negative pressure facilities have been recommended to minimise spread of the virus, but few have this capability. The alternative is to deep clean after each case. In the event of multiple STEMI patients arriving at once, a risk assessment should be performed and, if delays are inevitable, then thrombolysis should be considered.

In those developing cardiogenic shock in the context of COVID-19 infection, futility should be considered. However, as decision making in the acute setting can be challenging, all available supportive therapies should be used when appropriate. 


\section{THROMBOLYSIS FOR STEMI}

While PPCI remains the treatment of choice for STEMI, the number of COVID-19 cases in Wuhan and Lombardy raised sufficient concerns that thrombolysis should be considered in certain circumstances. $^{242728}$

In normal circumstances, transfer to PPCI centres is effective and safe. However, during the COVID-19 peak, hospital transfers have been affected and, for those unwell COVID-19 patients who are actively shedding virus, are potentially hazardous. Furthermore, critically unwell patients requiring non-invasive ventilation are challenging to transfer safely with aerosolised secretions posing a threat to staff. Intubated patients have closed circuits that lower the risk of transmission, but these patients remain a challenge to transfer in a timely manner. Those patients in intensive care units (ICU) in district generals without acute primary angioplasty services will be disadvantaged as acute transfer to local PPCI centres will be delayed. Those patients who have fulminant COVID-19 may be unable to lie flat and be unable to tolerate an invasive angioplasty.

In these scenarios, thrombolysis should be considered early and administered promptly in the absence of contraindications; the greatest value is within 1 hour of pain onset. Fibrin-specific agents such as alteplase and tenectaplase can be given easily; the latter is preferable as a single bolus reduces the need for close nursing contact.

The use of thrombolysis remains controversial with concerns over bleeding risks in the context of possible COVID-19 myocarditis. Furthermore, a quarter of patients will not reperfuse and still require facilitated PCI. ${ }^{23}$ However, despite these concerns, thrombolysis is used for STEMI around the world ${ }^{29}$ and has been used successfully in patients with COVID-19 in China. While PPCI has clear advantage in lower bleeding risk and greater likelihood of reperfusion, the efficacy balance between thrombolysis and PPCI is closer to equipoise when PPCI is delayed. The Strategic Reperfusion Early after Myocardial Infarction (STREAM) study demonstrated even a single hour of delay meant there was no significant difference in major events after randomised to either thrombolysis or PPCI. ${ }^{30}$

Patients should be urgently discussed with a senior cardiologist and an interventional cardiologist. Rapid communication is essential and may need to be entirely remote to facilitate speed. Documentation should reflect on why thrombolysis is used and the system constraints that mandated it. Upfront decisions should be documented for subsequent treatment for those patients in which ST segments do not sufficiently resolve. A cardiac catheter laboratory should be activated and steps taken for safe transfer. Patients achieving reperfusion should be considered for invasive angiography on stabilisation.
UNIQUE ISSUES REGARDING ACS IN THE

\section{COVID-19 ERA}

STEMI-mimic

Unwell patients with COVID-19 have manifested severe ST-elevation but have been found to have unobstructed coronary arteries on invasive angiography. ${ }^{12} 26$ The mechanism remains unclear but is attributed to myocarditis or a Takutsubo-type response to overwhelming inflammation. As COVID-19 case numbers rose in Wuhan and Lombardy, there was concern that PPCI services would be overwhelmed by similar patients and expose patients to the risks of unnecessary invasive procedures. ${ }^{3132}$ However, this has been less evident in the UK. Echocardiography can help support a diagnosis of a global myocarditis, but coronary angiography is still advocated to avoid missing a true coronary occlusion. ${ }^{33}$

\section{Delayed attendance}

As the pandemic evolved, a global reduction in ACS admissions has been noted. ${ }^{3}$ This is, perhaps, in response to strong governmental messages to 'stay at home'. Anecdotally, patients have avoided hospitals despite significant cardiac symptoms. Patients may fear contracting the virus or wish to avoid overloading medical services. Referrers in primary or intermediate care settings may misconstrue chest pain as part of COVID-19. Those in smaller district hospitals may be unable to transfer patients to catheter-lab centres due to saturation of emergency services. ${ }^{34}$ Globally, a $20 \%-40 \%$ reduction in STEMI presentations has been reported; greater reductions in NSTEMI are noted. ${ }^{35-37}$ Those attending have experienced significantly longer door-to-balloon times with longer times of assessment in emergency rooms, longer times for staff to prepare PPE and potentially longer procedure times due to clot burden, disease complexity or the need for respiratory support. ${ }^{3435}$

Late presentations for STEMI have increased ${ }^{34}$ and may have a large thrombotic burden with a failure to reperfuse despite PCI. Mechanical complications such as septal defects and ventricular rupture have been reported. It is expected that the incidence of heart failure may rise due to this late presentation with ACS. The national PCI and MI registries in the UK are being used to study the pattern of ACS admissions since the pandemic started. ${ }^{38}$

\section{NOVEL PATHWAYS \& NEW WAYS OF WORKING}

Significant changes in working patterns have meant novel care pathways have been instituted. Some of these may have value beyond the pandemic. Pathways should be modified according to the resources available locally.

\section{Minimised length of stay}

Prompt treatment and minimisation of testing unlikely to change near-term clinical decisions should help to minimise the inpatient length of stay. This is important to reduce the likelihood of patients acquiring de novo coronavirus infection from other patients. In efficient healthcare systems with early reperfusion, it should 
be feasible for uncomplicated MI to discharge within 24 hours of admission. Prompt review in emergency departments with same-day angiography should be considered where feasible. As elective care has been curtailed, catheter laboratories have the capacity for rapid turn around and radial access permits early discharge. Bedside point of care echocardiography can provide LV assessment. A short period of rhythm monitoring is appropriate in low-risk patients with uncomplicated PCI. Tests such as Positron emission tomography (PET), Myocardial Perfusion Imaging (MIBI) and Magnetic Resonance Imaging (MRI) are less readily available in the current pandemic. Unless critical for decision making, it is suggested these tests are deferred to reduce the length of inpatient stay.

Low-risk patients with low Global Registry of Acute Coronary Events (GRACE) scores and small troponin-rises can be stratified, and if appropriate, then early urgent angiography can be considered on an 'outpatient' basis without inpatient stays. Some Trusts have kept angiographic facilities in 'clean zones' allowing patients to be discharged from emergency departments and attend semielectively the next day for the invasive procedure while minimising hospital stay. Maximal antiplatelet therapy and appropriate counselling is required.

\section{Clustering of patients}

In some cases, inpatient stay is inevitable. Hospitals have developed clearly demarcated 'zones' to reflect the likelihood of viral cross-contamination. Patients with confirmed COVID-19 should be clustered with others who have the virus. However, delays in viral diagnostics can mean apparently well but infected and shedding patients can enter ostensibly 'clean' zones.

\section{Surgical disease}

Patients presenting with ACS may be found to have coronary disease best revascularised by coronary artery bypass surgery. Early in the pandemic, all elective surgery was cancelled to reduce the impact on intensive care facilities. This has evolved into allowing urgent surgery once discussed at an Multidisciplinary Team Meeting (MDT) but in a limited number of centres. MDTs should be performed early and ideally daily to minimise uncertainty and duration of inpatient stay. In patients who have COVID-19, there is concern that surgery will pose undue risk and harm. In these cases, PCI should be preferred where possible. As surgical disease can be complex, additional care and attention will be necessary when performing PCI with consideration of adjunctive technologies.

\section{AREAS FOR RESEARCH}

National registries are working to detect patterns of disease during the pandemic and will offer insights into how patients were treated. The C19ACS randomises COVID-19 patients with known coronary artery disease or risk factors to standard therapy or the addition of dual antiplatelet therapy with low-dose anticoagulation with rivaroxaban $2.5 \mathrm{mg}$ BD. The concept is that part of the elevated mortality in COVID-19 is driven by cardiac events and localised thrombosis. A pilot study is running before a wider roll-out (https://clinicaltrials.gov/ ct2/show/NCT04333407).

\section{ACS PHENOTYPES IN COVID-19 ERA}

One can consider a number of different phenotypes of ACS in the current era.

A classical ACS, with undiagnosed COVID-19, found on routine testing on admission

A 55-year-old man with a background history of hypertension and 20-a-day cigarette habit is admitted with $15 \mathrm{~min}$ of retrosternal chest pain. $\mathrm{He}$ is otherwise well. The ECG demonstrates deep T-wave inversion across the anterior leads, and the troponin is $253 \mathrm{ng} / \mathrm{L}$. Handheld echocardiography reveals anterior hypokinesia. There is no history of fever or dyspnoea, but a nasopharyngeal swab is PCR positive for COVID-19. He undergoes invasive angiography wearing a mask; the treating team is in full PPE. Following PCI to the mid-Left Anterior Descending (LAD) artery with a single drug eluting stent, he is allowed home promptly and given clear instructions for monitoring his temperature and saturations.

\section{Learning points}

- In this case, near routine care was delivered and an early discharge aimed to minimise viral exposure to other patients.

- Asymptomatic patients may be COVID-19 positive, and it is unclear if they are infective or not.

- PPE should be mandated while treating patients.

- Patients with higher risk NSTEMI (dynamic ECG changes and elevated troponin) are best treated with revascularisation where possible.

\section{Classical COVID-19 features with concomitant true STEMI}

A 66-year-old man with a background history of prior PCI over a decade previously is admitted with a classical presentation of COVID-19. He is breathless with a persistent cough and high fevers. Bilateral infiltrates are seen on chest radiographs. Initial ECGs are within normal limits (figure $1 \mathrm{~A}$ ). He requires continuous positive airways pressure (CPAP) but remains stable. Five days into admission, he develops central crushing chest pain at 06:00. He is markedly breathless and cannot lie flat. Severe inferior ST elevation is noted (figure 1B). Primary PCI requires urgent transfer to the local tertiary centre, but intensivists feel he is unsafe for transfer and prefer not to intubate. His case is urgently discussed between the cardiologist on the ward and interventionalists locally and at the tertiary centre; thrombolysis is agreed. Following alteplase and heparin, ST segments resolve (figure 1C), and the patient is stabilised on aspirin and clopidogrel. The troponin is $1800 \mathrm{ng} / \mathrm{L}$. After a further 5 days, he is well enough for invasive 
angiography. The left coronary system had a patent stent and minor disease. A thrombotic lesion is noted in the Right Coronary artery (RCA) (figure 2B,C). This is stented, and he is discharged on maximum secondary prevention.

\section{Learning points}

- Thrombolysis should be considered for patients who cannot receive PPCI in a timely manner.

- Decisions for thrombolysis should be senior led and made in conjunction with tertiary PPCI centres as a plan for facilitated PCI may be required.

- Angiography prior to discharge is desirable and should be performed once the patient has stabilised from COVID-19.

\section{Severe COVID-19 with STEMI-mimic}

A 41-year-old man with no prior medical history has a rapidly progressive COVID-19 illness. Following an initial trial of CPAP therapy, he requires intubation and is admitted to intensive care for monitoring. Troponin and BNP levels begin to rise, and his ECG shows widespread significant ST elevation. Haemodynamic parameters are normal, and bedside echocardiography shows 'low-normal' function with no clear regional wall motion abnormalities. In light of ST segment changes, the patient undergoes urgent invasive angiography. The coronary vessels are smooth and unobstructed. Conservative measures are instituted, but the patient develops recurrent ventricular tachycardia that is unresponsive to amiodarone and mexiletine. He developed multiorgan failure. He was considered for transfer

\section{Key points}

- Prompt and early revascularisation, with appropriate personal protective equipment, remains the default treatment approach for patients with acute coronary syndrome in the COVID-19 era.

- The use of risk stratification tools (such as GRACE scores) may aid the prioritisation of cases to minimise their hospital stay.

- Critically unwell patients with ST-elevation myocardial infarction, without onsite catheter lab facilities or too unstable for transfer should be considered for thrombolysis and activation of services for facilitated PCI if necessary.

- Patients with cardiovascular disease are particularly vulnerable during this period regardless of their infective status. Adaptation of cardiac services to ensure continuity of care for these patients even in the context of a further wave of COVID-19 is essential to minimise preventable cardiovascular death.

\section{CME credits for Education in Heart}

Education in Heart articles are accredited for CME by various providers. To answer the accompanying multiple choice questions (MCQs) and obtain your credits, click on the 'Take the Test' link on the online version of the article. The MCQs are hosted on BMJ Learning. All users must complete a one-time registration on BMJ Learning and subsequently log in on every visit using their username and password to access modules and their CME record. Accreditation is only valid for 2 years from the date of publication. Printable CME certificates are available to users that achieve the minimum pass mark. for advanced supportive therapies but destabilised and passed away.

\section{Learning points}

1. STEMI can occur due to myocarditis and does not equate to coronary occlusion.

2. The presence of myocarditis is a significant risk. Even those without coronary artery disease remain at high risk of a poor outcome. Consider advanced haemodynamic support with percutaneous ventricular assist devices or extracorporeal membrane oxygenation.

\section{FUTURE PERSPECTIVES POST-COVID-19}

The COVID-19 pandemic has driven a rapid configuration of services across hospitals, assisted by reduction in bureaucracy. Acute services have been reconfigured to reduce coronavirus spread with segregation of acute assessment areas, wards and catheter labs into 'clean' and 'dirty' zones. Patients are stratified by the likelihood of infection. Upstream swabbing and temperature assessment is essential. Unfortunately, maintaining strict clean sites will prove difficult in acute care, in particular for STEMI, and PPE should continue to be used when patients are at risk of being infective. Increasingly rapid swabbing protocols may facilitate more selective use.

Elective work, which was postponed by the pandemic, has been restored by using enhanced preprocedure assessment with comprehensive swabbing and patient self-isolation prior to elective procedures. The length of isolation appears variable across hospitals. Staff swabbing on a fortnightly basis may help identify illness among staff and reduce the chance of services closing or infection of patients. Outpatient elective surgery has been stratified by urgency and, in some places, has moved to different hospital sites to ensure there is no impact to intensive care services. Longer term, normal clinical services must return to minimise a growing inequality of service access.

Outpatient flows have benefited from embracing technology. Clinics become remote to to reduce patient viral exposure. Telephone and video clinics are now fully established and in many cases can replace traditional clinics. Face-to-face appointments can be reserved for specified patients but must include appropriate PPE and social distancing to reduce the exposure risk to cardiology patients who are specifically vulnerable to complications. Postinfarction 'virtual' cardiac rehabilitation and heart failure clinics have proven feasible.

Going forward, work is required to anticipate the possibility of further 'waves' of the virus. Cardiologists may need novel working models, expanding beyond job plans and may require shift patterns.

\section{CONCLUSIONS}

The management of ACS remains a key priority and services must be configured in an adaptable manner to respond to the changing demands in the pandemic. The treatment for ACS is well established, and while 
effort should be made to adhere to standard pathways, the judicious use of pharmacological and diagnostic adjuncts may allow deviation from these pathways to identify and treat those that are not true ACS and those that are simply too unstable to benefit from the standard treatment strategies.

Twitter Sukhjinder Singh Nijjer @sukhnijjer

Contributors SSN wrote the first draft that was critically appraised by RP and SS leading to subsequent drafts. All three authors have approved the final manuscript.

Funding The authors have not declared a specific grant for this research from any funding agency in the public, commercial or not-for-profit sectors.

\section{Competing interests None declared.}

Patient and public involvement Patients and/or the public were not involved in the design, or conduct, or reporting, or dissemination plans of this research.

Patient consent for publication Obtained.

Provenance and peer review Commissioned; internally peer reviewed.

Data availability statement There are no data in this work.

Author note References which include a * are considered to be key references.

Open access This is an open access article distributed in accordance with the Creative Commons Attribution Non Commercial (CC BY-NC 4.0) license, which permits others to distribute, remix, adapt, build upon this work non-commercially, and license their derivative works on different terms, provided the original work is properly cited, appropriate credit is given, any changes made indicated, and the use is non-commercial. See: http:// creativecommons.org/licenses/by-nc/4.0/.

ORCID iD

Sukhjinder Singh Nijjer http://orcid.org/0000-0001-9146-1037

\section{REFERENCES}

1 Driggin E, Madhavan MV, Bikdeli B, et al. Cardiovascular considerations for patients, health care workers, and health systems during the COVID-19 pandemic. J Am Coll Cardiol 2020:75:2352-71.

*2 The European Society for Cardiology. ESC guidance for the diagnosis and management of CV disease during the COVID-19 pandemic, 2020: 1-119. https://www.escardio.org/Education/ COVID-19-and-Cardiology/ESC-COVID-19-Guidance

*3 Mafham MM, Spata E, Goldacre R, et al. COVID-19 pandemic and admission rates for and management of acute coronary syndromes in England. Lancet 2020;396:381-9.

4 Wilson SJ, Connolly MJ, Elghamry Z, et al. Effect of the COVID-19 pandemic on ST-segment-elevation myocardial infarction presentations and in-hospital outcomes. Circ Cardiovasc Interv 2020;13:82.

5 De Rosa S, Spaccarotella C, Basso C, et al. Reduction of hospitalizations for myocardial infarction in Italy in the COVID-19 era. Eur Heart J 2020;41:2083-8.

6 Bromage DI, Cannatà A, Rind IA, et al. The impact of COVID-19 on heart failure hospitalization and management: report from a Heart Failure Unit in London during the peak of the pandemic. Eur $J$ Heart Fail 2020;22:978-84.

*7 Banerjee A, Pasea L, Harris S, et al. Estimating excess 1-year mortality associated with the COVID-19 pandemic according to underlying conditions and age: a population-based cohort study. Lancet 2020;395:1715-25.

8 Onder G, Rezza G, Brusaferro S. Case-Fatality rate and characteristics of patients dying in relation to COVID-19 in Italy. JAMA.

9 Wu Z, McGoogan JM. Characteristics of and Important Lessons From the Coronavirus Disease 2019 (COVID-19) Outbreak in China: Summary of a Report of 72314 Cases From the
Chinese Center for Disease Control and Prevention. JAMA 2020:323:1239-42.

10 Shi S, Qin M, Shen B, et al. Association of cardiac injury with mortality in hospitalized patients with COVID-19 in Wuhan, China. JAMA Cardiol 2020;5:802-8.

11 Guo T, Fan Y, Chen M, et al. Cardiovascular implications of fatal outcomes of patients with coronavirus disease 2019 (COVID-19). JAMA Cardiol 2020;5:811.

12 Santoso A, Pranata R, Wibowo A, et al. Cardiac injury is associated with mortality and critically ill pneumonia in COVID-19: a metaanalysis. Am J Emerg Med 2020:1-7.

13 Thygesen K, Alpert JS, Jaffe AS, et al. Fourth universal definition of myocardial infarction (2018). Eur Heart J 2019;40:237-69.

14 Tang X, Du R-H, Wang R, et al. Comparison of hospitalized patients with ARDS caused by COVID-19 and H1N1. Chest 2020;158:195-205.

15 Madjid M, Safavi-Naeini P, Solomon SD, et al. Potential effects of coronaviruses on the cardiovascular system: a review. JAMA Cardio/ 2020. doi:10.1001/jamacardio.2020.1286. [Epub ahead of print: 27 Mar 2020].

16 Kuster GM, Pfister O, Burkard T, et al. SARS-CoV2: should inhibitors of the renin-angiotensin system be withdrawn in patients with COVID-19? Eur Heart J 2020;41:1801-3.

17 Danser AHJ, Epstein M, Batlle D. Renin-Angiotensin system blockers and the COVID-19 pandemic: at present there is no evidence to abandon renin-angiotensin system blockers. Hypertension 2020;75:HYPERTENSIONAHA12015082.

*18 Roffi M, Patrono C, Collet J-P, et al. 2015 ESC guidelines for the management of acute coronary syndromes in patients presenting without persistent ST-segment elevation. Eur Heart J 2016;37:267-315

19 Fox KAA, Clayton TC, Damman P, et al. Long-Term outcome of a routine versus selective invasive strategy in patients with non-ST-segment elevation acute coronary syndrome a meta-analysis of individual patient data. J Am Coll Cardiol 2010;55:2435-45.

20 Paranjpe I, Fuster V, Lala A, et al. Association of treatment dose anticoagulation with in-hospital survival among hospitalized patients with COVID-19. J Am Coll Cardiol 2020;76:122-4

21 Mega JL, Braunwald E, Wiviott SD, et al. Rivaroxaban in patients with a recent acute coronary syndrome. N Engl J Med 2012;366:9-19.

*22 Ibanez B, James S, Agewall S, et al. 2017 ESC guidelines for the management of acute myocardial infarction in patients presenting with ST-segment elevation: the task force for the management of acute myocardial infarction in patients presenting with ST-segment elevation of the European Society of cardiology (ESC). Eur Heart J 2018:39:119-77.

*23 Curzen N. An extended statement by the British cardiovascular intervention Society president regarding the COVID-19 pandemic. Interv Cardiol 2020;15:1-2.

24 Chieffo A, Stefanini GG, Price S, et al. EAPCI position statement on invasive management of acute coronary syndromes during the COVID-19 pandemic. Eurolntervention 2020;16:233-46.

25 Choudry FA, Hamshere SM, Rathod KS, et al. High thrombus burden in patients with COVID-19 presenting with ST-elevation myocardial infarction. J Am Coll Cardiol 2020:1-26.

26 Bangalore S, Sharma A, Slotwiner A, et al. ST-Segment Elevation in Patients with Covid-19 - A Case Series. N Engl J Med 2020;382:2478-80.

27 Daniels MJ, Cohen MG, Bavry AA, et al. Reperfusion of STEMI in the COVID-19 Era - Business as Usual? Circulation;141.

28 Han $Y$, Zeng $H$, Jiang $H$, et al. Csc expert consensus on principles of clinical management of patients with severe emergent cardiovascular diseases during the COVID-19 epidemic. Circulation 2020;141:766.

29 Roe MT, Messenger JC, Weintraub WS, et al. Treatments, trends, and outcomes of acute myocardial infarction and percutaneous coronary intervention. J Am Coll Cardiol 2010;56:254-63.

30 Armstrong PW, Gershlick AH, Goldstein P, et al. Fibrinolysis or primary $\mathrm{PCl}$ in ST-segment elevation myocardial infarction. N Engl J Med 2013:368:1379-87.

31 Loghin C, Chauhan S, Lawless SM. Pseudo acute myocardial infarction in a young COVID-19 patient. JACC Case Rep $2020 ; 2: 1284-8$

32 Inciardi RM, Lupi L, Zaccone G, et al. Cardiac involvement in a patient with coronavirus disease 2019 (COVID-19). JAMA Cardiol 2020;5:819-6. 
33 Yousefzai R, Bhimaraj A, Rayan Yousefzai MD. Misdiagnosis in the COVID era: When Zebras are Everywhere, Don't Forget the Horses. JACC Case Rep 2020. doi:10.1016/j.jaccas.2020.04.018. [Epub ahead of print: 27 Apr 2020].

34 Roffi M, Guagliumi G, Ibañez B. The obstacle course of reperfusion for STEMI in the COVID-19 pandemics. Circulation 2020;39:119-7.

35 C-CF T, Cheung K-S, Lam S, et al. Impact of coronavirus disease 2019 (COVID-19) outbreak on ST-Segment-Elevation myocardial infarction care in Hong Kong, China. Circ Cardiovasc Qual Outcomes 2020;13:1-3.
36 Garcia S, Albaghdadi MS, Meraj PM, et al. Reduction in STsegment elevation cardiac catheterization laboratory activations in the United States during COVID-19 pandemic. J Am Coll Cardiol 2020:75:2871-2.

37 Rodriguez-Leor O, Cid-Alvarez B, Ojeda S, et al. Impacto de la pandemia de COVID-19 sobre La actividad asistencial en cardiología intervencionista en España. RECIC 2020:1-8.

$38 \mathrm{BCIS}$. Has there really been a fall in heart attack presentations in the UK? 2020. Available: https://www.bcis.org.uk/news/hasthere-really-been-a-fall-in-heart-attack-presentations-in-the-uk [Accessed 14 May 2020]. 